Original Article

\title{
Association between preoperative sleep disturbance and low muscle mass in patients with gastrointestinal cancer
}

\author{
Maho Okumura, RPT, BSc1)*, Takashi Saito, RPT, MS ${ }^{1,2)}$, Akimasa Fukuta, RPT, BSc ${ }^{3)}$, \\ Daisuke Makiura, RPT, PhD ${ }^{1)}$, Junichiro Inoue, RPT, PhD ${ }^{1)}$, Yoshitada Sakai, MD, $\mathrm{PhD}^{1,4)}$, \\ REI ONO, RPT, $\mathrm{PhD}^{2)}$ \\ 1) Division of Rehabilitation, Kobe University Hospital: 7-5-2 Kusunoki-cho, Chuo-ku, Kobe, \\ Hyogo 650-0017, Japan \\ 2) Department of Community Health Sciences, Kobe University Graduate School of Health Sciences, \\ Japan \\ 3) Department of Rehabilitation, Nagoya University Hospital, Japan \\ 4) Division of Rehabilitation Medicine, Kobe University Graduate School of Medicine, Japan
}

\begin{abstract}
Purpose] Low muscle mass and sleep disturbance are common among geriatric patients with cancer. In patients with gastrointestinal cancer, low muscle mass is considered an indicator of poor prognosis. In the recent years, sleep disturbance has attracted much attention as a factor for low muscle mass among community-dwelling elderly individuals; however, such associations are unclear in patients with cancer. The present study investigated the relationship between preoperative sleep disturbance and low muscle mass in patients with gastrointestinal cancer. [Participants and Methods] This cross-sectional survey enrolled 86 elderly patients (aged more than 60 years) with gastrointestinal cancer who were scheduled for curative surgery. Low preoperative muscle mass was defined according to Asian Working Group for Sarcopenia criteria. Sleep disturbance was assessed using the Japanese version of the Pittsburgh Sleep Quality Index, including the subscales. [Results] Twenty-seven patients (31\%) were classified as having low muscle mass. After adjusting for confounding factors, bad sleep quality, determined by the subscales, was significantly associated with low muscle mass. [Conclusion] Our results suggest that the evaluation of sleep quality is imperative for addressing low preoperative muscle mass in patients with gastrointestinal cancer. Key words: Low muscle mass, Sleep disturbance, Gastrointestinal cancer
\end{abstract}

(This article was submitted Aug. 23, 2019, and was accepted Oct. 17, 2019)

\section{INTRODUCTION}

Low muscle mass is more common among preoperative geriatric patients with cancer than among healthy older people, having a prevalence of $41.5 \%$ among preoperative patients with gastric cancer versus $26.8 \%$ and $22.8 \%$ among healthy men and women, respectively, ${ }^{1,2)}$. Factors affecting low muscle mass among patients with cancer are intricate. Alterations in hormonal mediators, as well as the release of tumor factors and cytokines, can all lead to low muscle mass ${ }^{3)}$. Considering that low muscle mass predicts postoperative complications and is associated with decreased recurrence-free survival and decreased survival rates in gastrointestinal cancer ${ }^{1,4,5}$, low preoperative muscle mass remains a major problem that must be addressed.

In recent years, sleep disturbance has attracted much attention as a factor for low muscle mass among community-dwelling elderly individuals. Sleep disturbance affects hormonal mediators and cytokines, which can lead to low muscle mass ${ }^{6,7)}$. For

*Corresponding author. Maho Okumura (E-mail: m.c.st.bond.0430@gmail.com)

(C2020 The Society of Physical Therapy Science. Published by IPEC Inc.

(c) (1) $\odot$ This is an open-access article distributed under the terms of the Creative Commons Attribution Non-Commercial No Derivatives cc) 
example, lack of sleep time associated with increased cortisol, which is a catabolism hormone ${ }^{8)}$. Previous studies have shown that bad sleep quality, efficiency and prolonged time to fall asleep are associated with low muscle mass among community dwelling elderly ${ }^{9,10}$. Given that certain types of sleep disturbances are involved in the development of low muscle mass, the assessment of various types of sleep disturbances is imperative.

Sleep disturbance has been overlooked by the oncology community ${ }^{11)}$. Nonetheless, considering that sleep disturbance is also a common symptom among patients with cancer ${ }^{12)}$, such a problem needs considerable attention. It is necessary to examine the relationship between sleep disturbance and low muscle mass, which affects prognosis. However, such associations have been unclear in patients with cancer. If the relationship between preoperative sleep disturbance and low muscle can be clarified, the assessment of sleep might be useful for addressing low muscle mass when we provide rehabilitation. The present study, therefore, investigated the association between preoperative sleep disturbance and low muscle mass, while evaluating certain types of sleep disturbance.

\section{PARTICIPANTS AND METHODS}

This cross-sectional study was conducted between July 2016 and April 2017 at a single university hospital located in an urban area. A total of 161 patients with gastrointestinal cancer aged 60 years and older and who scheduled for curative surgery were enrolled. The exclusion criteria included the presence of simultaneous cancers, declining of consent, or any missing values. Among the 161 patients recruited, 139 (86\%) agreed to participate in the current study. A total of 53 patients were excluded because of simultaneous cancers $(n=1)$ or at least one missing values $(n=52)$. Ultimately, 86 patients were enrolled in the present study (male: 72 , female: 14, age: $70.5 \pm 7.08$ years, mean $\pm \mathrm{SD}$ ). After obtaining a written consent, all included patients completed measurements before surgery. Ethical approval for the present study was provided by the Ethics Committee of the Kobe University Graduate School of Health Sciences (approval number 440). All participants were properly informed about the study and signed written consent forms prior to participation in accordance with the Declaration of Helsinki.

Weight, muscle mass, and body mass index (BMI) were assessed using multi-frequency bioelectrical impedance with eight electrodes (Inbody430; Inbody Japan, Tokyo, Japan). Low muscle mass was defined as a skeletal muscle mass index (SMI) of $<7.0$ and $<5.7 \mathrm{~kg} / \mathrm{m}^{2}$ for men and women, respectively, according to the criteria of the Asian Working Group for Sarcopenia ${ }^{13)}$. Patients were divided into "low muscle mass" and "no low muscle mass" groups, whereas SMI and BMI were calculated using the following formulas:

SMI $\left(\mathrm{kg} / \mathrm{m}^{2}\right)=$ appendicular skeletal muscle mass index $(\mathrm{kg}) /$ height $(\mathrm{m})^{2}$;

BMI $\left(\mathrm{kg} / \mathrm{m}^{2}\right)=$ weight $(\mathrm{kg}) /$ height $(\mathrm{m})^{2}$

Sleep disturbance was measured using the Japanese version of the Pittsburgh Sleep Quality Index (PSQI) ${ }^{14,15)}$, which had been validated by Doi et $\mathrm{al}^{15)}$. The PSQI is a self-report questionnaire that assesses the sleep quality of an individual over a 1-month interval. Self-reported items of the PSQI generate seven component scores (range of subscale scores, 0-3): sleep quality, sleep latency, sleep duration, habitual sleep efficiency, sleep disturbance, use of sleep medication, and daytime dysfunction. The sum of the seven component scores yields one global score representing subjective sleep quality (range, $0-21)$ and the higher scores suggest worse sleep. Patients with total score $>5$ were classified as bad sleep ${ }^{14,15)}$.

Information regarding age, gender, height, C-reactive protein (CRP), serum albumin value, cancer type, clinical stage, preoperative chemoradiotherapy, and comorbidity were obtained from patient medical records. In addition, information regarding education, drinking and smoking history, cognitive function, physical activity, depression, and nutritional status were collected using self-report questionnaires. Comorbidity was measured using the Charlson Comorbidity Index $(\mathrm{CCI})^{16)}$. The final CCI score was categorized into three grades and the sum of the weights assigned to 19 predetermined clinical conditions ${ }^{17)}$. Cognitive function was measured using the Mini-Mental State Examination ${ }^{18)}$, an interview-based test on cognitive ability. Accordingly, a score of $<24$ indicates cognitive impairment ${ }^{19)}$. Physical activity was measured using the Japanese version of International Physical Activity Questionnaire Short Version ${ }^{20)}$, a self-report questionnaire that assesses physical activity within the last 7 days. Patients answered nine questions regarding walking frequency and duration, and frequency of moderate or vigorous physical activity. The total score was used to categorize patients into low, moderate, and high activity groups according to the guidelines ${ }^{21)}$. Depression was measured using the Geriatric Depression Scale Short Version (GDS) ${ }^{22)}$. The total score ranged from 0 to 15 with a score of $>5$ indicating depression ${ }^{23)}$. Nutritional status was measured using the Mini Nutritional Assessment-Short Form (MNA-SF) ${ }^{24)}$, which evaluates six domains including anorexia, weight loss, mobility, psychological stress or acute disease, dementia or depression, and BMI, with scores ranging from 0 to 14 points. The total score was used to categorize patients into three groups: normal (MNA-SF: 12-14 points), at-risk (8-11points), and malnourished (0-7 points) ${ }^{25)}$.

The Shapiro-Wilk test was performed to determine the normality of data. Characteristics of patients with and without low muscle mass were compared using Fisher's exact tests, Student's t-tests, or Mann-Whitney U tests. Bad sleep and PSQI subscales between those with and without low muscle mass were also compared using Fisher's exact tests. Multiple logistic regression analyses were performed to determine the association between sleep disturbance and low muscle mass. Independent variables for logistic regression models included sleep factors that showed a significant relationship with the outcome $(\mathrm{p}<0.05)$ during univariate analysis. Covariate factors associated with the outcome $(\mathrm{p}<0.05)$ in univariate analyses 
were included in the multivariate regression model. BMI has been excluded from our model considering the adjustment of BMI would result in over adjustment when investigating the association between sleep and muscle mass as suggested by the previous report ${ }^{26)}$. All analyses were conducted using EZR ver. $1.33^{27)}$ with $\mathrm{p}<0.05$ being considered statistically significant.

\section{RESULTS}

Patients' clinical characteristics are listed in Table 1. The average age of the participants was 70.5 years old (standard deviation $=7.08$; range $=60-92$ years), the majority of whom were men $(84 \%)$ and had colorectal $(40 \%)$ and gastric $(38 \%)$ cancers. Among the 86 patients, 27 (31\%) were identified as having low muscle mass. Patients with low muscle mass had significantly lower BMI (20.5 \pm 2.35 vs. $24.6 \pm 3.35$; $<<0.001)$, higher CRP $(1.22 \pm 2.57$ vs. $0.27 \pm 0.64 ; p=0.020)$, and more depressed $(\mathrm{p}=0.022)$ than those without low muscle mass.

Table 2 shows the comparison of sleep disturbance between those with and without low muscle mass. A total of 39 patients (45\%) experienced bad sleep. Moreover, those with low muscle mass had a significantly worse sleep quality $(p=0.006)$ than those without low muscle mass. Therefore, sleep quality was used as independent factors in the multiple logistic regression analyses. In accordance with the previous study ${ }^{9}$ ), sleep quality had been categorized into either "good" (fairly good or very good) or "bad" (fairly bad or very bad). Tables 3 shows the results for logistic regression analyses. After adjusting for CRP and GDS, the significant association between bad sleep quality and low muscle mass has been found (odds ratio, 4.15; $95 \%$ confidence interval, 1.02-16.9) (Table 3).

Table 1. Association between covariates and low muscle mass

\begin{tabular}{|c|c|c|c|c|}
\hline & $\begin{array}{c}\text { All } \\
(\mathrm{n}=86)\end{array}$ & $\begin{array}{c}\text { Low muscle mass } \\
(\mathrm{n}=27)\end{array}$ & $\begin{array}{l}\text { No low muscle mass } \\
\qquad(\mathrm{n}=59)\end{array}$ & $\mathrm{p}$ \\
\hline Age* (years) & $70.5 \pm 7.08$ & $71.6 \pm 8.25$ & $70.1 \pm 6.50$ & 0.62 \\
\hline Gender (males), n (\%) & $72(84)$ & $26(96)$ & $46(78)$ & 0.055 \\
\hline $\mathrm{BMI}^{*}\left(\mathrm{~kg} / \mathrm{m}^{2}\right)$ & $23.3 \pm 3.60$ & $20.5 \pm 2.35$ & $24.6 \pm 3.35$ & $<0.001$ \\
\hline Education* (years) & $12.7 \pm 2.60$ & $12.4 \pm 2.69$ & $12.8 \pm 2.56$ & 0.54 \\
\hline $\mathrm{CRP}^{*}(\mathrm{mg} / \mathrm{dL})$ & $0.57 \pm 1.58$ & $1.22 \pm 2.57$ & $0.27 \pm 0.64$ & 0.020 \\
\hline Serum Albumin* $(\mathrm{g} / \mathrm{dL})$ & $3.89 \pm 0.51$ & $3.71 \pm 0.57$ & $3.97 \pm 0.46$ & 0.11 \\
\hline Cancer type & & & & 0.98 \\
\hline Gastric, n (\%) & $32(37)$ & $11(41)$ & $21(36)$ & \\
\hline Esophageal, n (\%) & $16(19)$ & $5(19)$ & $11(19)$ & \\
\hline Gastroesophageal junction, n (\%) & $4(4.7)$ & $1(3.7)$ & $3(5.1)$ & \\
\hline Colorectal, n (\%) & $34(40)$ & $10(37)$ & $24(41)$ & \\
\hline Clinical stage & & & & 1 \\
\hline $0-\mathrm{II}, \mathrm{n}(\%)$ & $64(74)$ & $20(74)$ & $44(75)$ & \\
\hline III - IV, n (\%) & $22(26)$ & $7(26)$ & $15(25)$ & \\
\hline Preoperative CRT, n (\%) & $20(23)$ & $6(22)$ & $14(24)$ & 1 \\
\hline $\mathrm{CCI}$ & & & & 0.91 \\
\hline $\mathrm{CCI}=0, \mathrm{n}(\%)$ & $40(47)$ & $13(48)$ & $27(46)$ & \\
\hline $\mathrm{CCI}=1, \mathrm{n}(\%)$ & $19(22)$ & $5(19)$ & $14(24)$ & \\
\hline $\mathrm{CCI} \geq 2, \mathrm{n}(\%)$ & $27(31)$ & $9(33)$ & $18(31)$ & \\
\hline MMSE < 24, n (\%) & $13(15)$ & $7(26)$ & $6(10)$ & 0.10 \\
\hline History of drinking, $n(\%)$ & $62(72)$ & $16(59)$ & $46(78)$ & 0.11 \\
\hline History of smoking, $\mathrm{n}(\%)$ & $62(72)$ & $23(85)$ & $39(66)$ & 0.076 \\
\hline IPAQ & & & & 0.51 \\
\hline Low, n (\%) & $26(30)$ & $10(37)$ & $16(27)$ & \\
\hline Moderate, n (\%) & $53(62)$ & $16(59)$ & $37(63)$ & \\
\hline High, n (\%) & $7(8.1)$ & $1(3.7)$ & $6(10)$ & \\
\hline GDS $>5, n(\%)$ & $26(30)$ & $13(48)$ & $13(22)$ & 0.022 \\
\hline MNA-SF & & & & 0.077 \\
\hline Malnourished, n (\%) & $5(5.8)$ & $3(11)$ & $2(3.4)$ & \\
\hline At-risk, n (\%) & $32(37)$ & $13(48)$ & $19(32)$ & \\
\hline Normal, n (\%) & $49(57)$ & $11(41)$ & $38(64)$ & \\
\hline
\end{tabular}

BMI: body mass index; CRP: C-reactive protein; CRT: chemoradiotherapy, CCI: Charlson Comorbidity Index; MMSE: Mini-Mental State Examination; IPAQ: International Physical Activity Questionnaire; GDS: Geriatric Depression Scale; MNA-SF: Mini Nutritional Assessment-Short Form.

Results are expressed as mean \pm standard deviations or percentages.

Fisher's exact tests, Student's t-tests, and Mann-Whitney U tests were used for categorical, normally distributed, and non-normally distributed data, respectively.

*Mann-Whitney U tests. 
Table 2. Association between PSQI components and low muscle mass

\begin{tabular}{|c|c|c|c|c|}
\hline & $\begin{array}{c}\text { All } \\
(n=86)\end{array}$ & $\begin{array}{l}\text { Low muscle mass } \\
\qquad(\mathrm{n}=27)\end{array}$ & $\begin{array}{l}\text { No low muscle mass } \\
\qquad(\mathrm{n}=59)\end{array}$ & $\mathrm{p}$ \\
\hline \multicolumn{5}{|l|}{ PSQI total score } \\
\hline$>5$ & $39(45)$ & $15(56)$ & $24(41)$ & 0.24 \\
\hline Sleep quality & & & & 0.006 \\
\hline Very good & $11(13)$ & $5(19)$ & $6(10)$ & \\
\hline Fairly good & $58(67)$ & $12(44)$ & $46(78)$ & \\
\hline Fairly bad & $14(16)$ & $9(33)$ & $5(8.5)$ & \\
\hline Very bad & $3(3.5)$ & $1(3.7)$ & $2(3.4)$ & \\
\hline Sleep latency & & & & 0.20 \\
\hline$\leq 15 \min$ & $50(58)$ & $12(44)$ & $38(64)$ & \\
\hline $16-30 \mathrm{~min}$ & $25(29)$ & $10(37)$ & $15(25)$ & \\
\hline $31-60 \mathrm{~min}$ & $10(12)$ & $5(19)$ & $5(8.5)$ & \\
\hline$>60 \mathrm{~min}$ & $1(1.2)$ & $0(0)$ & $1(1.7)$ & \\
\hline Sleep duration & & & & 0.98 \\
\hline$\geq 7 \mathrm{~h}$ & $31(36)$ & $10(37)$ & $21(36)$ & \\
\hline $6-7 \mathrm{~h}$ & $23(27)$ & $8(30)$ & $15(25)$ & \\
\hline $5-6 h$ & $30(35)$ & $9(33)$ & $21(36)$ & \\
\hline$<5 \mathrm{~h}$ & $2(2.3)$ & $0(0)$ & $2(3.4)$ & \\
\hline Sleep efficiency & & & & 0.59 \\
\hline$\geq 85 \%$ & $57(66)$ & $18(67)$ & $39(66)$ & \\
\hline $75-84 \%$ & $15(17)$ & $3(11)$ & $12(20)$ & \\
\hline $65-74 \%$ & $11(13)$ & $5(19)$ & $6(10)$ & \\
\hline$<65 \%$ & $3(3.5)$ & $1(3.7)$ & $2(3.4)$ & \\
\hline Sleep disturbances & & & & 0.11 \\
\hline 0 & $13(15)$ & $1(3.7)$ & $12(20)$ & \\
\hline $1-9$ & $66(77)$ & $23(85)$ & $43(73)$ & \\
\hline $10-18$ & $7(8.1)$ & $3(11)$ & $4(6.8)$ & \\
\hline $19-27$ & $0(0)$ & $0(0)$ & $0(0)$ & \\
\hline Sleep medications & & & & 0.38 \\
\hline None & $74(86)$ & $22(81)$ & $52(88)$ & \\
\hline Less than once per week & $2(2.3)$ & $0(0)$ & $2(3.4)$ & \\
\hline Once or twice a week & $3(3.5)$ & $2(7.4)$ & $1(1.7)$ & \\
\hline Three or more times a week & $7(8.1)$ & $3(11)$ & $4(6.8)$ & \\
\hline Daytime dysfunction & & & & 0.56 \\
\hline 0 & $59(69)$ & $17(63)$ & $42(71)$ & \\
\hline $1-2$ & $22(26)$ & $9(33)$ & $13(22)$ & \\
\hline $3-4$ & $5(5.8)$ & $1(3.7)$ & $4(6.8)$ & \\
\hline $5-6$ & $0(0)$ & $0(0)$ & $0(0)$ & \\
\hline
\end{tabular}

PSQI: Pittsburg Sleep Quality Index.

Results expressed as absolute value and percentage.

Fisher's exact tests.

Table 3. Association between sleep quality and low muscle mass according to multiple logistic regression models

\begin{tabular}{lcc}
\hline & Odds Ratio & $95 \%$ Confidence Interval \\
\hline CRP & $1.89^{\dagger}$ & $1.06-3.37$ \\
GDS $>5$ & 1.74 & $0.48-6.25$ \\
Sleep quality & 1.00 & \\
$\quad$ Good sleep quality & $4.15^{\dagger}$ & $1.02-16.9$ \\
$\quad$ Bad sleep quality & & \\
\hline$\dagger p<0.05$. & & \\
CRP: C-reactive protein; GDS: Geriatric Depression Scale. \\
"Good sleep quality", (fairly good or very good); "Bad sleep quality", (fairly bad or \\
very bad).
\end{tabular}

\section{DISCUSSION}

The purpose of this study was to investigate the relationship between sleep disturbance and low muscle mass in patients with gastrointestinal cancer scheduled for curative surgery. Our results revealed that bad sleep quality was significantly associated with low muscle mass after adjusting for CRP and GDS. 
The results revealed the association between sleep quality assessed using PSQI subscales and muscle mass. Apart from the current study, several others have investigated the association between PSQI subscales and muscle mass. Buchmann et al. reported that sleep quality and latency were associated with muscle mass among community-dwelling elderly men, with results herein being similar in terms of sleep quality ${ }^{9)}$. Bad sleep quality is common in patients with cancer ${ }^{28)}$. Moreover, sleep disorders may occur as a result of various factors, such as anxiety and distress regarding prognosis and treatment even for early-stage cancer ${ }^{12}$. Therefore, our results support and expand those from previous studies in that sleep quality was found to be associated with muscle mass among patients with cancer whose symptoms were overlooked. In addition, the previous study reported that sleep quality was more strongly related to cognitive function regardless of sleep duration among older age people ${ }^{29}$. Thus, bad sleep quality is a sleep disorder to be focused on among elderly people. Our study suggested that sleep quality plays an important role in maintaining muscle mass among patients with cancer.

A number of potential mechanisms mediate the association between sleep quality and muscle mass. A decline in sleep quality may prevent individuals from reaching slow-wave sleep (SWS), the deepest among the sleep stages ${ }^{30)}$. The release of growth hormone $(\mathrm{GH})$, which is an anabolic hormone, has been shown to be the greatest during SWS ${ }^{31)}$. Insulin-like Growth Factor 1 (IGF-1) is another anabolic hormone that is secreted predominantly by the liver in response to GH ${ }^{32}$ ). IGF-1 levels were found to be associated with the amount of time spent in SWS ${ }^{33)}$. Additionally, one study showed that experimentally fragmented sleep increased the levels of the catabolic hormone cortisol ${ }^{30}$. Taken together, hormonal imbalances related to bad sleep quality might have been the cause for low muscle mass in the present study.

To the best of our knowledge, this has been the first study to examine the association between sleep disturbance and low muscle mass in patients with cancer. It is important to note that the present study focused on sleep disturbance in patients with cancer, which has received little attention. In addition, sleep disturbance was measured using the PSQI, which allowed the detailed investigation of the association between sleep disturbance and low muscle mass. The results showed that sleep quality was significantly associated with muscle mass. Nonetheless, some limitations of the present study need to be noted. First, given the cross-sectional nature of this study, we were unable to evaluate causality. Second, although some of the previous studies analyzed factors for low muscle mass within each gender ${ }^{9,34)}$, the present study could not do the same due to the limited number of women included in our participants. Third, sleep information had been obtained through self-reporting instead of objective measures, such as polysomnography or actigraphy data. Therefore, further large-scale longitudinal studies involving both genders and objective measurements for sleep disturbance are needed.

The present study investigated the relationship between sleep disturbance and muscle mass in patients with gastrointestinal cancer scheduled for curative surgery. Accordingly, our results showed that bad sleep quality was associated with low muscle mass. The evaluation of sleep quality is crucial for addressing low preoperative muscle mass among patients with cancer since we cannot deny the possibility of the impact of sleep quality on the low muscle mass, which affects prognosis of patients with gastrointestinal cancer.

\section{Presentation at a conference}

We made the poster presentation in 12th World Congress of the International Society of Physical and Rehabilitation Medicine (ISPRM), ISPR8-2327.

\section{Funding}

This work was supported by the Japan Society for the Promotion of Science (JSPS) (grant number 15K01367, 19K11345).

\section{Conflict of interest}

No author has declared conflicts of interest.

\section{ACKNOWLEDGEMENTS}

We are grateful to patients who participated in this study and all the professional staff of participating institutes.

\section{REFERENCES}

1) Zhuang CL, Huang DD, Pang WY, et al.: Sarcopenia is an independent predictor of severe postoperative complications and long-term survival after radical gastrectomy for gastric cancer: analysis from a large-scale cohort. Medicine (Baltimore), 2016, 95: e3164. [Medline] [CrossRef]

2) Iannuzzi-Sucich M, Prestwood KM, Kenny AM: Prevalence of sarcopenia and predictors of skeletal muscle mass in healthy, older men and women. J Gerontol A Biol Sci Med Sci, 2002, 57: M772-M777. [Medline] [CrossRef]

3) Argilés JM, Busquets S, Felipe A, et al.: Molecular mechanisms involved in muscle wasting in cancer and ageing: cachexia versus sarcopenia. Int J Biochem Cell Biol, 2005, 37: 1084-1104. [Medline] [CrossRef]

4) van Vledder MG, Levolger S, Ayez N, et al.: Body composition and outcome in patients undergoing resection of colorectal liver metastases. Br J Surg, 2012, 99: 550-557. [Medline] [CrossRef] 
5) Lieffers JR, Bathe OF, Fassbender K, et al.: Sarcopenia is associated with postoperative infection and delayed recovery from colorectal cancer resection surgery. Br J Cancer, 2012, 107: 931-936. [Medline] [CrossRef]

6) Spiegel K, Leproult R, Colecchia EF, et al.: Adaptation of the 24-h growth hormone profile to a state of sleep debt. Am J Physiol Regul Integr Comp Physiol, 2000, 279: R874-R883. [Medline] [CrossRef]

7) Vgontzas AN, Zoumakis E, Bixler EO, et al.: Adverse effects of modest sleep restriction on sleepiness, performance, and inflammatory cytokines. J Clin Endocrinol Metab, 2004, 89: 2119-2126. [Medline] [CrossRef]

8) Guyon A, Balbo M, Morselli LL, et al.: Adverse effects of two nights of sleep restriction on the hypothalamic-pituitary-adrenal axis in healthy men. J Clin Endocrinol Metab, 2014, 99: 2861-2868. [Medline] [CrossRef]

9) Buchmann N, Spira D, Norman K, et al.: Sleep, muscle mass and muscle function in older people. Dtsch Arztebl Int, 2016, 113: 253-260. [Medline]

10) Auyeung TW, Kwok T, Leung J, et al.: Sleep duration and disturbances were associated with testosterone level, muscle mass, and muscle strength-a crosssectional study in 1274 older men. J Am Med Dir Assoc, 2015, 16: 630.e1-630.e6, e6. [Medline] [CrossRef]

11) Garland SN, Johnson JA, Savard J, et al.: Sleeping well with cancer: a systematic review of cognitive behavioral therapy for insomnia in cancer patients. Neuropsychiatr Dis Treat, 2014, 10: 1113-1124. [Medline]

12) O'Donnell JF: Insomnia in cancer patients. Clin Cornerstone, 2004, 6: S6-S14. [CrossRef]

13) Chen LK, Liu LK, Woo J, et al.: Sarcopenia in Asia: consensus report of the Asian Working Group for Sarcopenia. J Am Med Dir Assoc, 2014, 15: 95-101. [Medline] [CrossRef]

14) Buysse DJ, Reynolds CF 3rd, Monk TH, et al.: The Pittsburgh Sleep Quality Index: a new instrument for psychiatric practice and research. Psychiatry Res, 1989, 28: 193-213. [Medline] [CrossRef]

15) Doi Y, Minowa M, Uchiyama M, et al.: Psychometric assessment of subjective sleep quality using the Japanese version of the Pittsburgh Sleep Quality Index (PSQI-J) in psychiatric disordered and control subjects. Psychiatry Res, 2000, 97: 165-172. [Medline] [CrossRef]

16) Charlson ME, Pompei P, Ales KL, et al.: A new method of classifying prognostic comorbidity in longitudinal studies: development and validation. J Chronic Dis, 1987, 40: 373-383. [Medline] [CrossRef]

17) Potretzke AM, Kim EH, Knight BA, et al.: Patient comorbidity predicts hospital length of stay after robot-assisted prostatectomy. J Robot Surg, 2016, 10: 151-156. [Medline] [CrossRef]

18) Folstein MF, Folstein SE, McHugh PR: "Mini-mental state". A practical method for grading the cognitive state of patients for the clinician. J Psychiatr Res, 1975, 12: 189-198. [Medline]

19) Tangalos EG, Smith GE, Ivnik RJ, et al.: The Mini-Mental State Examination in general medical practice: clinical utility and acceptance. Mayo Clin Proc, 1996, 71: 829-837. [Medline] [CrossRef]

20) Craig CL, Marshall AL, Sjöström M, et al.: International physical activity questionnaire: 12-country reliability and validity. Med Sci Sports Exerc, 2003, 35: 1381-1395. [Medline] [CrossRef]

21) International Physical Activity Questionnaire (IPAQ) website. 2005 Guidelines for data processing and analysis of the International Physical Activity Questionnaire (IPAQ). https://sites.google.com/site/theipaq/scoring-protocol (Accessed Aug. 20, 2019)

22) Yesavage JA, Sheikh JI: 9/Geriatric Depression Scale (GDS). Clin Gerontol, 1986, 5: 165-173. [CrossRef]

23) Lyness JM, Noel TK, Cox C, et al.: Screening for depression in elderly primary care patients. A comparison of the Center for Epidemiologic Studies-Depression Scale and the Geriatric Depression Scale. Arch Intern Med, 1997, 157: 449-454. [Medline] [CrossRef]

24) Kuzuya M, Kanda S, Koike T, et al.: Evaluation of mini-nutritional assessment for Japanese frail elderly. Nutrition, 2005, 21: 498-503. [Medline] [CrossRef]

25) Rubenstein LZ, Harker JO, Salvà A, et al.: Screening for undernutrition in geriatric practice: developing the short-form mini-nutritional assessment (MNASF). J Gerontol A Biol Sci Med Sci, 2001, 56: M366-M372. [Medline] [CrossRef]

26) Chien MY, Wang LY, Chen HC: The relationship of sleep duration with obesity and sarcopenia in community-dwelling older adults. Gerontology, 2015, 61: 399-406. [Medline] [CrossRef]

27) Kanda Y: Investigation of the freely available easy-to-use software 'EZR' for medical statistics. Bone Marrow Transplant, 2013, 48: 452-458. [Medline] [CrossRef]

28) Sprod LK, Palesh OG, Janelsins MC, et al.: Exercise, sleep quality, and mediators of sleep in breast and prostate cancer patients receiving radiation therapy. Community Oncol, 2010, 7: 463-471. [Medline] [CrossRef]

29) Miller MA, Wright H, Ji C, et al.: Cross-sectional study of sleep quantity and quality and amnestic and non-amnestic cognitive function in an ageing population: the English Longitudinal Study of Ageing (ELSA). PLoS One, 2014, 9: e100991. [Medline] [CrossRef]

30) Stamatakis KA, Punjabi NM: Effects of sleep fragmentation on glucose metabolism in normal subjects. Chest, 2010, 137: 95-101. [Medline] [CrossRef]

31) Sassin JF, Parker DC, Mace JW, et al.: Human growth hormone release: relation to slow-wave sleep and sleep-walking cycles. Science, 1969 , 165 : 513-515. [Medline] [CrossRef]

32) Clemmons DR: The relative roles of growth hormone and IGF-1 in controlling insulin sensitivity. J Clin Invest, 2004, 113: 25-27. [Medline] [CrossRef]

33) Prinz PN, Moe KE, Dulberg EM, et al.: Higher plasma IGF-1 levels are associated with increased delta sleep in healthy older men. J Gerontol A Biol Sci Med Sci, 1995, 50: M222-M226. [Medline] [CrossRef]

34) Lucassen EA, de Mutsert R, le Cessie S, et al. NEO study group: Poor sleep quality and later sleep timing are risk factors for osteopenia and sarcopenia in middle-aged men and women: The NEO study. PLoS One, 2017, 12: e0176685. [Medline] [CrossRef] 